\title{
DISTRICT-LEVEL DIFFERENCES BETWEEN SCHOOL SYSTEMS RECOGNIZED FOR DISTINCTION IN PERFORMANCE AND THOSE NOT THUS RECOGNIZED
}

\author{
Gretchen C. Guitard \\ Dr. Jerry W. Valentine, Dissertation Supervisor
}

ABSTRACT

The purpose of this study was to compare school districts that consistently have high student performance to other school districts with similar enrollment, socioeconomic status, and community types that do not have consistently high performance and analyze the subtleties of these differences. For the study, school districts in Missouri designated with "Distinction in Performance" were compared with similar districts not receiving "Distinction in Performance" scores. The designation of "Distinction in Performance" is the highest merit a school district can receive in the state's accreditation process and is primarily based on student performance on various state and national assessments. Quantitative analyses were used to analyze the differences.

The first hypothesis tested for significant differences on the 23 scales of the Advanced Questionnaire survey completed by teachers for the state department of education. Analysis of variance test of differences and post-hoc assessments were used to test the first hypothesis. The second hypothesis analyzed significant differences using ANCOVA for the same 23 scales while co-varying on the demographic variables of student enrollment, socio-economic status, and community type. The results of both hypotheses were reported for each of the following clusters of scales: (a) the Learning Experience Cluster, (b) the Professionalism and Collaboration Cluster, (c), the 
Communication and Parental Involvement Cluster, (d) the Leadership Responsibility Cluster, and (e) the Professional Growth Cluster. Both hypotheses were rejected.

For the ANOVA tests, 16 of the 23 scales were significantly different. For the ANCOVA analyses, 17 of the 23 scales were statistically different. Four scales were significantly different for the ANCOVA analyses that were not significant for the ANOVA analyses. The scales were Instructional Strategies, Guaranteed Curriculum, Career Preparation, and Professional Development. Teachers across the school districts in this study viewed these scales as important regardless of the demographic characteristics of the districts. The findings from this study provide insight and guidance to the educational leaders seeking to determine factors upon which to focus in their efforts to establish highly successful school districts based upon the criteria established by the Missouri state department of education. The statistical findings for the remaining scales provide additional insight about other areas of focus for a districts' effort to achieve excellence. 